\title{
ON THE RELIABILITY OF I/B/E/S EARNINGS ANNOUNCEMENT DATES AND FORECASTS
}

\author{
Daniella Acker \\ Nigel W. Duck
}

November 2009

Discussion Paper No. 09/611

Department of Economics

University of Bristol

8 Woodland Road

Bristol BS8 1TN 


\section{ON THE RELIABILITY OF I/B/E/S EARNINGS}

\section{ANNOUNCEMENT DATES AND FORECASTS}

Daniella Acker (University of Bristol)

Nigel W. Duck (University of Bristol)

\section{Corresponding author:}

Daniella Acker

School of Economics, Finance and Management

University of Bristol

8 Woodland Road

Bristol BS8 1TN UK

Phone: $+44(0) 1179288438$

Fax: +44 (0)117928 8577

Email: daniella.acker@bristol.ac.uk

\section{$\underline{\text { Acknowledgements }}$}

We are grateful to Sarah Hallworth for research assistance and to Peter Pope for much useful advice. Thomson Reuters staff have provided valuable discussions and are managing the revision process that we describe. 


\begin{abstract}
We add to the concerns raised in Ljungqvist, Malloy and Marston, 2009, Rewriting History, Journal of Finance, 64, 1935-1960, about the reliability of the I/B/E/S data provided by Thomson Reuters (TR). Many of the dates reported as earnings announcement dates are not earnings announcement dates; there are inconsistencies between these dates and those reported in Worldscope, another TR database; and summaries of financial analysts' forecasts can be misleading. Following discussions with the authors, TR has reviewed approximately 2 million records and is in the process of correcting some 50,000 of them. Further reviews are under way.
\end{abstract}

Keywords: I/B/E/S; Worldscope; earnings announcements; analysts' forecasts

JEL classification: G00, G10, G14, G32 
ON THE RELIABILITY OF I/B/E/S EARNINGS

ANNOUNCEMENT DATES AND FORECASTS

\section{INTRODUCTION}

Ljungqvist, Malloy and Marston (2009) (hereafter LMM) seriously question the reliability of a major data source for researchers of US financial markets the $\mathrm{I} / \mathrm{B} / \mathrm{E} / \mathrm{S}$ analyst stock recommendations database. Specifically, they find that across seven downloads spanning 2000 to 2007 , between $1.6 \%$ and $21.7 \%$ of matched observations are different from one download to the next. We report three further types of unreliability in the Thomson Reuters' Thomson ONE Banker (T1B) package, all connected with dates of final earnings announcements. We also report inaccuracy in the Worldscope (WS) database.

Two sources of final earnings announcement dates in the Thomson Reuters' (TR) T1B package are the WS and the I/B/E/S databases. These databases were integrated on 21 March, 2005, when Thomson Financial launched its “Thomson ONE for Investment Management" package, enabling companyrelated data to be accessed via one application. WS provides company accounts data, and I/B/E/S provides data on analysts' forecasts; both provide data relating to the dates of final earnings announcements. The relevant $\mathrm{I} / \mathrm{B} / \mathrm{E} / \mathrm{S}$ date is labelled "IBH.EPS.Actual Report Date"; the WS date is identified as data item W05905.

Our investigation focuses on earnings announcement dates in the I/B/E/S and WS databases, and on analysts' earnings forecasts of UK companies' 
impending end-of-fiscal-year earnings announcements in the $\mathrm{I} / \mathrm{B} / \mathrm{E} / \mathrm{S}$ database (item "FYR1"). These forecasts are provided primarily in the form of summaries, ${ }^{1}$ which include, inter alia, means and medians of forecasts. Until 21 July 2004 only monthly summaries are available, dated according to the month (for example, September 2005); daily summaries are available from 22 July 2004.

We highlight below three areas of concern.

First, year-end earnings announcement dates are frequently misreported in the I/B/E/S database. Private communication with TR indicates that these errors probably arise from mislabelling: the date on which the announcement was incorporated into the database has been labelled as the IBH.EPS.Actual Report Date. We hand-collected 2,041 announcement dates for UK companies in the period between 1 January 1999 and 31 December 2006 and were able to compare 1,874 of them with those reported in the $\mathrm{I} / \mathrm{B} / \mathrm{E} / \mathrm{S}$ database. We found $24 \%$ to be incorrect, $97 \%$ of which were later than the true date. About a quarter of these discrepancies were of either one or two days; a further quarter of them were between 3 and 10 days; and forty percent of them were between 11 and 50 days. A handful were over a year out.

Second, there are discrepancies between announcement dates reported in $\mathrm{I} / \mathrm{B} / \mathrm{E} / \mathrm{S}$ and those reported in WS. In a comparison of over 2,000 announcement dates for UK companies between 1 January 1999 and 31

\footnotetext{
${ }^{1}$ More detailed data for individual analysts are also available.
} 
December 2008 we found $22 \%$ to be different in the two components. Most of these discrepancies arise because WS reports the correct date, while I/B/E/S reports a 'mislabelled' date. However, a comparison of the hand-collected dates with their WS counterparts revealed that $8 \%$ of the WS dates were incorrect (and, of these, 74\% were later than the true date). We also compared $\mathrm{I} / \mathrm{B} / \mathrm{E} / \mathrm{S}$ and WS dates for S\&P100 companies' final earnings announcements between January 1999 and December 2008 and these showed a discrepancy rate of $13 \%$. Two thirds of these were 6 days or more, with a maximum discrepancy of 384 days.

Third, when the $\mathrm{I} / \mathrm{B} / \mathrm{E} / \mathrm{S}$ announcement date is later than the true report date, it is possible for the forecasts also to be dated after the true report date. Analysts can therefore appear to be forecasting earnings per share after the actual figure has been made public. This is particularly evident in the daily summaries of forecasts, which are available from 22 July 2004 for UK companies. Examples of these "retrospective" forecasts are given in section 3.

Analysts' forecasts and year-end earnings announcement dates play a crucial role in accounting and finance research in general, and in event studies and implied cost of capital estimation in particular. Inaccuracies in either can distort the results of such studies in a number of ways. Firstly, merely by introducing noise into regressors, incorrect event dates may cause important parameter estimates to be biased towards zero. Nor will the standard practice in earnings-announcement event studies, of setting an event window of a few days (often two or three) around the announcement date, solve this problem, as 
we find that $72 \%$ of the $\mathrm{I} / \mathrm{B} / \mathrm{E} / \mathrm{S}$ dates are out by more than three days.

Secondly, because the majority of reported dates are late, studies looking for evidence of post-announcement drift are unlikely to find it, even if it does exist; while true post-announcement drift may wrongly be ascribed to preannouncement information leakage. Thirdly, studies which obtain the true announcement date from a source other than $\mathrm{I} / \mathrm{B} / \mathrm{E} / \mathrm{S}$ (WS, for example) and then identify what appear to be the final forecasts made before that date, are likely to report greater inaccuracy and more disagreement (a higher variance) in those forecasts than was truly the case.

The nature and scale of the inaccuracies in the data which our study reveals suggest that these distortions could be serious.

Following recent correspondence with the authors, TR teams have reviewed approximately 2 million records in the I/B/E/S database, covering 70,000 periods, comparing dates with the ex-Reuters database. They have identified 50,000 errors in European announcement dates, and a project to correct the dates is now under way. They are currently reviewing the dates reported in WS and are about to begin a process to verify the announcement dates reported for US firms.

The rest of this note presents the detail of data sources and the sample used (section 1), an analysis of announcement dates (section 2) and an analysis of forecasts (section 3). We conclude in section 4 . 


\section{DATA SOURCES AND SAMPLE}

\section{$\underline{\text { Data sources }}$}

Table 1 shows the data sources we used.

TABLE 1 ABOUT HERE

\section{Sample}

(i) Analysis of UK companies

The main sample consists of 265 UK companies for which we have handcollected earnings announcement dates between 1999 and 2006. Most are, or were, quoted on the London Stock Exchange (LSE), a very few in Ireland. The LSE companies are FTSE-250 or FTSE100 companies.

We have a total of 2,041 announcement dates for the 265 companies but we could not compare them all with WS and I/B/E/S, since not all the companies were available in these databases. 22 were not available in $\mathrm{I} / \mathrm{B} / \mathrm{E} / \mathrm{S}$ but were available in WS; 20 were not available in WS but were available in I/B/E/S; two were not available in either. 
(ii) Analysis of US companies (comparison of WS and I/B/E/S)

100 companies in the S\&P100 as at 17 August 2009; 858 earnings

announcement dates between 1 January 1999 and 31 December 2008 which could be compared across the two databases.

\section{Dates used for the analysis}

Comparison of WS and I/B/E/S for UK and US companies: earnings announcement dates between 1 January 1999 and 31 December 2008.

Comparison of hand-collected UK company dates with WS and I/B/E/S: earnings announcement dates between 1 January 1999 and 31 December 2006

\section{COMPARISON OF ANNOUNCEMENT DATES}

Table 2 shows details of the comparison among WS, the I/B/E/S database and hand-collected announcement dates for UK companies. It shows a discrepancy rate of $22 \%$ between the two T1B databases, and an error rate (i.e. incorrectly reported dates) of $24 \%$ in $\mathrm{I} / \mathrm{B} / \mathrm{E} / \mathrm{S}$ and $8 \%$ in WS. A similar comparison between the T1B databases for the S\&P100 companies (detail not reported here, but available from the authors on request) showed a discrepancy rate of $13 \%$. 
As reported above, $97 \%$ of the incorrectly-reported I/B/E/S dates were later than the true date, while $74 \%$ of the Worldscope ones were later (again, detail is not shown here but is available from the authors on request).

\section{TABLE 2 ABOUT HERE}

While a large number of the discrepancies and errors are of one or two days, an alarmingly high percentage is more than that. (For US companies $66 \%$ of the discrepancies were 6 days or more.) The maximum number of days' difference is astonishingly high (it was 384 for the US company comparison), usually caused by recording one - often incorrect - date twice. For example, referring to UK companies:

London Stock Exchange. I/B/E/S records 23 July 2001 as the date of the announcement for both 2000 and 2001 fiscal years. In fact the LSE was floated in July 2001 and published pre-flotation results on 24 May 2001. There was no announcement on 23 July 2001.

Compass plc. WS records 11 December 2001 as the date of the announcement for both 2000 and 2001 fiscal year ends. It was the announcement date for fiscal year 2001 only.

Michael Page International plc. I/B/E/S records 6 June 2001 as the date of the announcement for both 1999 and 2000 fiscal year ends. There was no announcement on 6 June 2001. 
Table 3 shows the distribution of these discrepancies categorised by fiscal year end. It suggests that the discrepancy rate peaked for 2003 year ends and hence that any distortionary effects these discrepancies have on results are likely to be especially strong in studies using pre 2004 data. It also suggests that TR's finding of 50,000 errors in 2 million records, which implies a lower error rate than we report, may be because those records include announcements made after 2006. There are likely to be more records for later years, as earlier data tends to be more sparse, and these later records are also likely to be more accurate.

TABLE 3 ABOUT HERE

\section{ANALYSTS' FORECASTS: 'CASE STUDIES' OF ERRORS}

In this section we illustrate the nature of the inaccuracies we have uncovered with three examples. In all cases the forecasts apparently continue to be made for some time after the true announcement date. Details are shown in table 4 .

TABLE 4 ABOUT HERE

\section{Monthly data}

Pillar Property Group; fiscal year ended March 2002 (ticker@PLV)

True announcement date 11 June 2002

I/B/E/S date 21 August 2002

Last available forecast summary August 2002 
Scottish Radio Holdings; fiscal year ended September 2002 (ticker@RRC)

True announcement date 21 November 2002

I/B/E/S date 8 May 2003

Last available forecast summary April 2003

\section{$\underline{\text { Daily data }}$}

Smith (DS); fiscal year ended April 2005 (ticker@SSA)

True announcement date 30 June 2005

I/B/E/S date 14 September 2005

Last available forecast summary 13 September 2005

\section{CONCLUSIONS}

LMM have questioned the reliability of the historical I/B/E/S database. Their concerns relate to the changes between different downloads of the US analyst stock recommendations. This note also questions the reliability of the I/B/E/S database - and, to a lesser extent, WS announcement dates - raising doubts about the internal consistency and accuracy of a particular download, rather than about consistency across different downloads. Our findings, like those of LMM, raise serious concerns about research that has used these databases, and, of course, about any future research, until the databases are corrected. 
TABLES

Table 1 Data sources

\begin{tabular}{|c|c|}
\hline Source & Data \\
\hline Thomson One Banker & $\begin{array}{l}\text { WS earnings announcement dates, data } \\
\text { item W05905. } \\
\text { I/B/E/S: } \\
\text { Earnings announcement dates } \\
\text { (IBH.EPSActualReportDate). } \\
\text { Earnings forecasts (mean, median etc) } \\
\text { for upcoming final earnings (e.g. } \\
\text { IBH.EPSMeanFYR1). }\end{array}$ \\
\hline $\begin{array}{l}\text { Company websites, newspaper } \\
\text { websites, investor websites; data } \\
\text { retrieved from Extel cards and } \\
\text { the Perfect Analysis database for } \\
\text { dates up to end } 2005\end{array}$ & $\begin{array}{l}\text { Hand-collected earnings announcement } \\
\text { dates. }\end{array}$ \\
\hline
\end{tabular}


Table 2 Comparison among WS, I/B/E/S and hand-collected announcement dates: UK companies

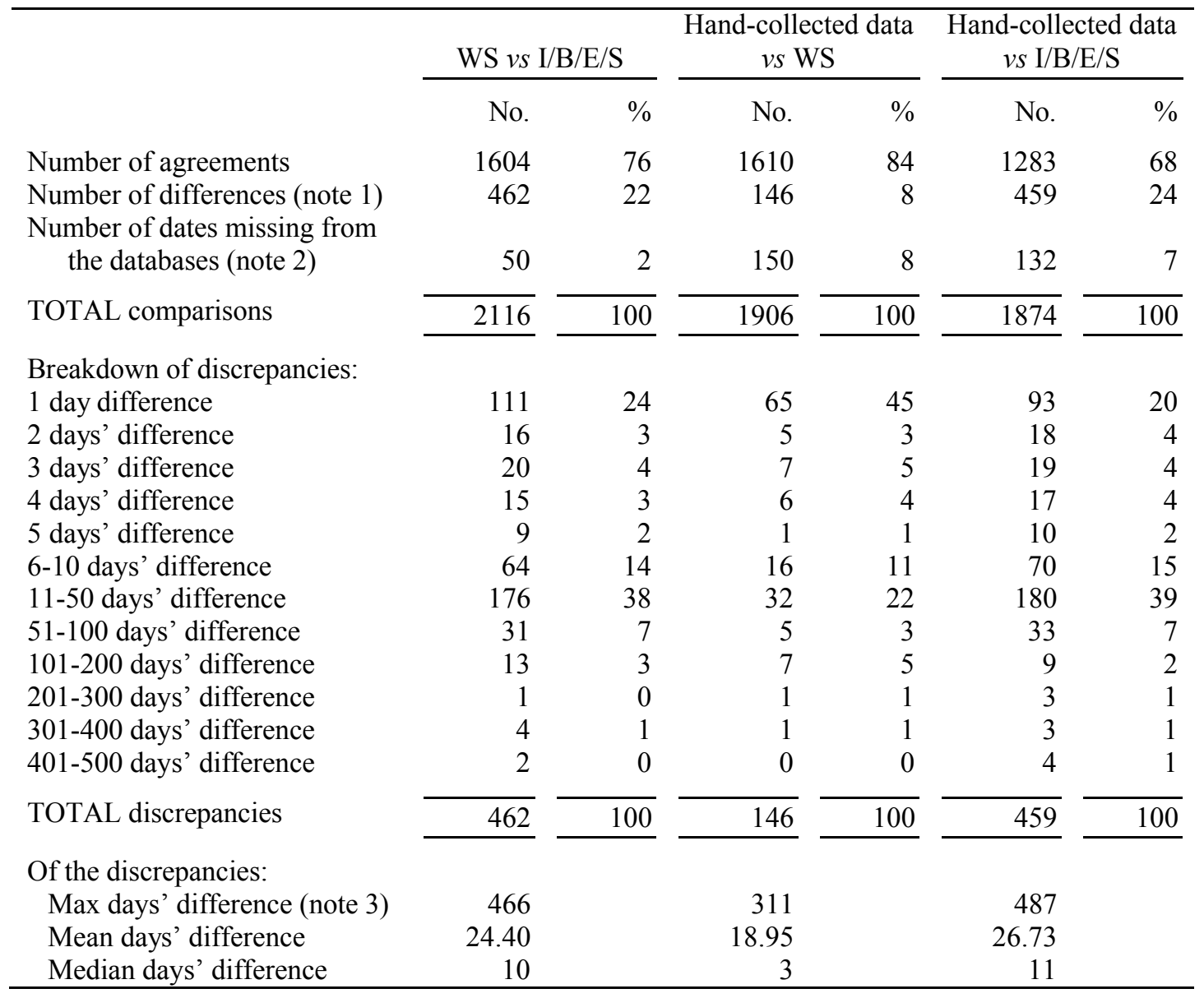

Notes

1. For hand-collected data comparison, 'differences' denote errors in the database.

2. For WS $v s \mathrm{I} / \mathrm{B} / \mathrm{E} / \mathrm{S}$ this is the number of dates available in one and not the other.

3. Note that some of the very large discrepancies were caused by recording the same announcement date twice, as explained in section 2. 
Table 3 Distribution of errors across fiscal year ends

\begin{tabular}{|c|c|c|c|c|}
\hline & \multicolumn{2}{|c|}{ Worldscope } & \multicolumn{2}{|c|}{$\mathrm{I} / \mathrm{B} / \mathrm{E} / \mathrm{S}$} \\
\hline & No. & $\%$ & No. & $\%$ \\
\hline $1999 \mathrm{y} / \mathrm{e}$ & 47 & 32 & 63 & 14 \\
\hline $2000 \mathrm{y} / \mathrm{e}$ & 34 & 23 & 52 & 11 \\
\hline $2001 \mathrm{y} / \mathrm{e}$ & 11 & 8 & 24 & 5 \\
\hline $2002 \mathrm{y} / \mathrm{e}$ & 18 & 12 & 106 & 23 \\
\hline $2003 \mathrm{y} / \mathrm{e}$ & 19 & 13 & 112 & 24 \\
\hline $2004 \mathrm{y} / \mathrm{e}$ & 7 & 5 & 71 & 15 \\
\hline $2005 \mathrm{y} / \mathrm{e}$ & 4 & 3 & 25 & 5 \\
\hline $2006 \mathrm{y} / \mathrm{e}$ & 6 & 4 & 6 & 1 \\
\hline Total & 146 & 100 & 459 & 100 \\
\hline
\end{tabular}




\section{Table 4 Investigation of forecasts}

\begin{tabular}{|c|c|c|c|c|c|c|c|c|}
\hline \multicolumn{3}{|c|}{$\begin{array}{c}\text { Pillar Property Group } \\
\text { True announcement date } 11 \text { June } 2002\end{array}$} & \multicolumn{3}{|c|}{$\begin{array}{c}\text { Scottish Radio Holdings } \\
\text { True announcement date } 21 \text { November } 2002\end{array}$} & \multicolumn{3}{|c|}{$\begin{array}{c}\text { Smith (DS) } \\
\text { True announcement date 30 June } 2005\end{array}$} \\
\hline $\begin{array}{l}\text { Forecast } \\
\text { summary date }\end{array}$ & Y/e being forecast & Mean forecast & $\begin{array}{l}\text { Forecast } \\
\underline{\text { summary date }}\end{array}$ & $\underline{Y / e}$ being forecast & Mean forecast & $\begin{array}{l}\text { Forecast } \\
\text { summary date }\end{array}$ & $\underline{\text { Y/e being forecast }}$ & Mean forecast \\
\hline May 02 & Mar2002 & 7.820 & Jul 02 & Sep2002 & 19.320 & 16-Jun-2005 & Apr2005 & 12.994 \\
\hline Jun 02 & Mar2002 & 7.820 & Aug 02 & Sep2002 & 19.320 & 17-Jun-2005 & Apr2005 & 12.994 \\
\hline Jul 02 & Mar2002 & 7.090 & Sept 02 & Sep2002 & 22.710 & etc & etc & etc \\
\hline Aug 02 & Mar2002 (Note) & 4.061 & Oct 02 & Sep2002 & $\mathrm{N} / \mathrm{A}$ & 30-Jun-2005 & Apr2005 & 12.994 \\
\hline Sept 02 & Mar2003 & 4.590 & Nov 02 & Sep2002 & N/A & 01-Jul-2005 & Apr2005 & 13.091 \\
\hline Oct 02 & Mar2003 & 4.400 & Dec 02 & Sep2002 & N/A & etc & etc & etc \\
\hline \multirow[t]{9}{*}{ Nov 02} & Mar2003 & 4.790 & Jan 03 & Sep2002 & N/A & 25-Aug-2005 & Apr2005 & 13.091 \\
\hline & & & Feb 03 & Sep2002 & N/A & 26-Aug-2005 & Apr2005 & 12.691 \\
\hline & & & Mar 03 & Sep2002 & 28.670 & 29-Aug-2005 & Apr2005 & 12.691 \\
\hline & & & Apr 03 & Sep2002 & 28.670 & 30-Aug-2005 & Apr2005 & 12.691 \\
\hline & & & May 03 & Sep2003 & 21.580 & 31-Aug-2005 & Apr2005 & 12.569 \\
\hline & & & Jun 03 & Sep2003 & 24.060 & etc & etc & etc \\
\hline & & & & & & 13-Sep-2005 & Apr2005 & 12.569 \\
\hline & & & & & & 14-Sep-2005 & Apr2006 & 11.735 \\
\hline & & & & & & 15-Sep-2005 & Apr2006 & 11.735 \\
\hline
\end{tabular}

Note: It is difficult to tell the true year to which the August forecasts relate, because the forecasts roughly halve in August, indicating that they might actually relate to the 2003 fiscal year. The actual eps for fiscal year 2002 in the I/B/E/S database is 12.288, which is closer to the pre- than the post-August forecasts. 


\section{REFERENCES}

Ljungqvist, Alexander, Christopher Malloy and Felicia Marston, 2009, Rewriting History, Journal of Finance, 64, 1935-1960. 